
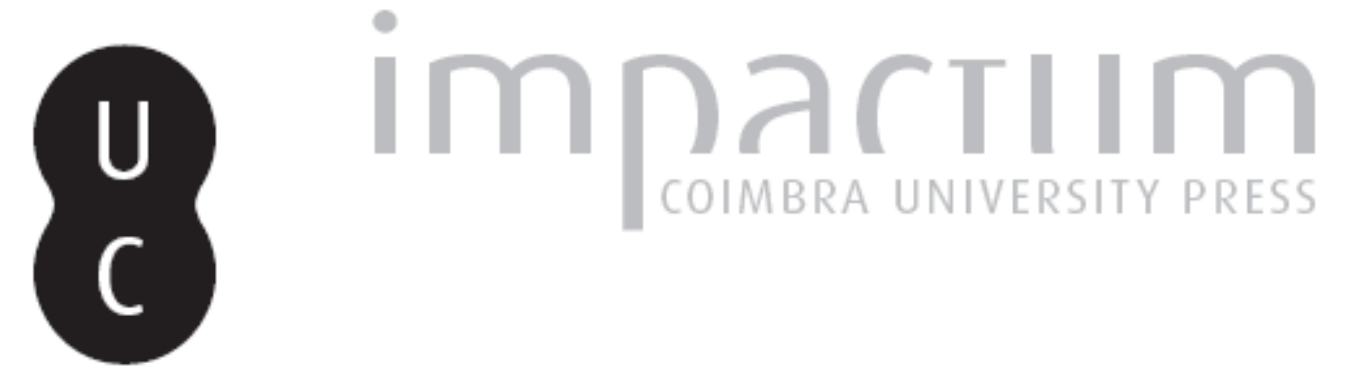

\title{
[Recensão a] FILHO, João Lopes - Cultura Tradicional no Estado Novo. V Congresso Internacional da Vinha e do Vinho
}

\author{
Autor(es): $\quad$ Torgal, Luís Reis
}

Publicado por: Imprensa da Universidade de Coimbra

URL persistente:

URI:http://hdl.handle.net/10316.2/36759

DOI:

DOI:http://dx.doi.org/10.14195/1647-8622_11_32

Accessed : $\quad$ 26-Apr-2023 16:04:59

A navegação consulta e descarregamento dos títulos inseridos nas Bibliotecas Digitais UC Digitalis, UC Pombalina e UC Impactum, pressupõem a aceitação plena e sem reservas dos Termos e Condições de Uso destas Bibliotecas Digitais, disponíveis em https://digitalis.uc.pt/pt-pt/termos.

Conforme exposto nos referidos Termos e Condições de Uso, o descarregamento de títulos de acesso restrito requer uma licença válida de autorização devendo o utilizador aceder ao(s) documento(s) a partir de um endereço de IP da instituição detentora da supramencionada licença.

Ao utilizador é apenas permitido o descarregamento para uso pessoal, pelo que o emprego do(s) título(s) descarregado(s) para outro fim, designadamente comercial, carece de autorização do respetivo autor ou editor da obra.

Na medida em que todas as obras da UC Digitalis se encontram protegidas pelo Código do Direito de Autor e Direitos Conexos e demais legislação aplicável, toda a cópia, parcial ou total, deste documento, nos casos em que é legalmente admitida, deverá conter ou fazer-se acompanhar por este aviso.

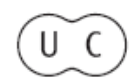


fazer história contemporânea

ESTUDOSDOSÉCULO

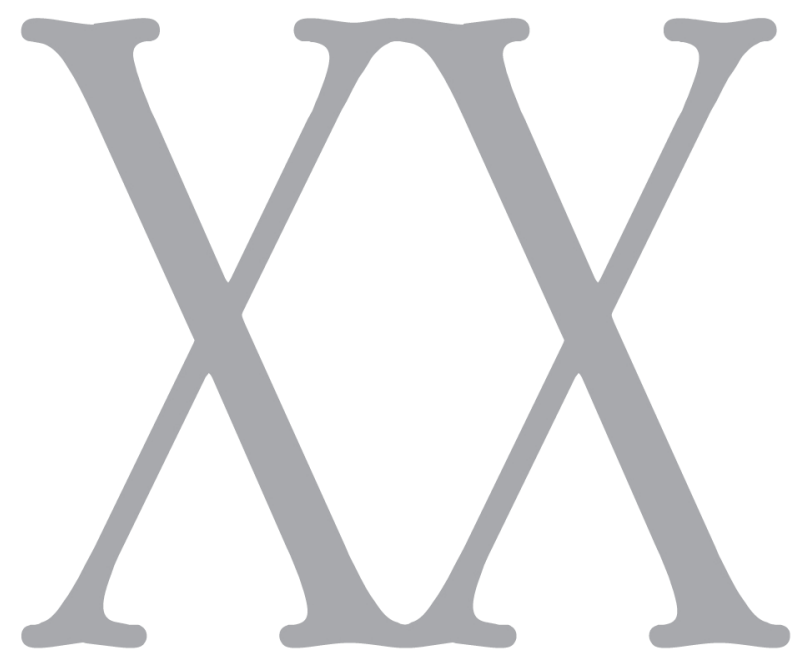

número 11 • 2011

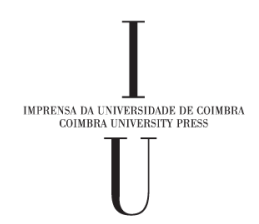


FILHO, João Lopes - Cultura Tradicional no Estado Novo. $V$ Congresso Internacional da Vinha e do Vinho. Lisboa: INATEL, 2009. ${ }^{1}$

\section{A edição do livro e o INATEL}

Começo por saudar o autor, que conheci em S. Vicente, num colóquio integrado nas Comemoraçóes da República, onde não faltou, extra-programa, uma noite de mornas e coladeras, que me lembraram Mansoa (na Guiné), onde, por falta de lugar no quartel, estive na casa da D. Emília, uma cabo-verdiana radicada ali com os seus filhos (entre eles a Adosinda, agora casada com o meu amigo Senhor Quinzinho, que voltei a visitar já depois da independência), que, num velho gira-discos, tocavam todos os dias as músicas da sua terra, ao cair da tarde, quando regressava do quartel e das agruras da guerra.

D. Emília, que me alugara uma garagem feita casa, servia-me todas os domingos um bife de gazela, para quebrar a monotonia da messe e lembrar-me que esse era um dia especial. Daí o meu amor por Cabo Verde, sem nessa altura ter conhecido do arquipélago senão a ilha do Sal, que era então apenas um interposto aéreo e militar, diferente da ilha turística em que a converteu o milagre cabo-verdiano.

Cumprimento depois a Dr. ${ }^{a}$ Cristina Baptista, Vogal do Conselho de Administração, com competências delegadas nas áreas da Direcção Cultural e Serviços Jurídicos, a quem peço o favor de cumprimentar o Dr. Vítor Ramalho, Presidente da Administração do INATEL.

1 Texto que serviu de base à apresentação do livro acima citado, realizada em Lisboa, no Teatro da Trindade, em 27 de Abril de 2011.
Profundamente transformada, no contexto de um novo enquadramento político, é uma das poucas instituições que se mantêm oriundas do regime de Salazar.

A Fundação Nacional para a Alegria no Trabalho (FNAT), criada em 13 de Junho de 1935 pelo decreto-lei n. ${ }^{\circ} 25.495$, era uma instituição de produção e de controlo dos lazeres dos trabalhadores. Curiosamente vim a viver, quando o meu pai era médico em Souselas, por cima de um dos seus Centros de Recreio Popular, tendo assistido como criança a muitas das suas manifestaçôes culturais e desportivas e mesmo a alguns bailes que ali, quase furtivamente, se faziam. Enquadrar os trabalhadores nos seus lazeres, tal como a Opera Nazionale Dopolavoro, do Fascismo italiano, ou a Kraft durch Freud (Força pela Alegria), do Nazismo, era uma das suas funções num Estado que não queria deixar nada ao acaso. Se bem que, nessa altura organizaçóes desse tipo, viradas para os trabalhadores, surgiam evidentemente na soviética Rússia, mas também em países demoliberais, organizando-se congressos, que tanto se podiam realizar em países como a Bélgica (o Congresso Internacional dos Lazeres, realizado em Bruxelas em 1935), como na totalitária Alemanha nazi (o Congresso Internacional dos Lazeres e Recreação, efectuado em Berlim e Hamburgo em 1936). De resto, o turismo estava em expansão e organizava também os seus congressos, virados para um lazer mais socialmente selectivo.

Foi este objectivo do lazer e da cultura dos trabalhadores que levou, portanto, a que a FNAT se transformasse em INATEL (Instituto Nacional para Aproveitamento dos Tempos Livres dos Trabalhadores), assim como sucedeu com as Casas do Povo, de instituição salazarista (decreto-lei n. ${ }^{\circ} 23.051$, de 23 de Setembro de 1933), 
que se mantiveram depois do 25 de Abril. Parecia então que a revolução pretendia privilegiar os direitos dos trabalhadores, com os seus objectivos de assistência e lazer. De resto, a FNAT e o INATEL mereceram estudos fundamentais de José Carlos Valente, citados no livro de João Lopes Filho, de onde respigámos ideias que já aqui foram expostas.

Pois foi o INATEL que publicou este livro de João Lopes Filho, com a data de 2009, impresso, curiosamente, na casa gráfica, a ARTIPOL, onde sempre publicámos a Revista de História das Ideias, de que fui director durante vinte anos. Tudo, portanto, me liga a esta publicação: o autor e a sua terra-natal, o livro, o INATEL e o seu Presidente que - como recordou numa breve nota de apresentação — o editou tendo em conta que a "área cultural" é "um espaço privilegiado da Fundação INATEL", como foi da FNAT, embora com diferenças essenciais. Se, no caso presente, se trata ou deve tratar de uma "cultura para a Liberdade" (e nada há para a consciencialização da Liberdade do que conhecer a História, não manipulada, mas entendida cientificamente, com objectividade), no outro, da FNAT, tratava-se de uma "cultura integrada" num regime político autoritário (em certo sentido totalitário), limitada nas suas fronteiras.

Disse que tudo me ligava a este livro. O mais importante é o seu tema, pois o primeiro artigo que escrevi sobre o Estado Novo, com o meu colega Amadeu Carvalho Homem, chamava-se "Ideologia política e "cultura popular». Análise da biblioteca de uma Casa do Povo”. João Lopes cita também este artigo, publicado na Análise Social em 1982. Tratava-se exactamente da Casa do Povo de Souselas, em que se convertera, no período marcelista, o Centro de Recreio Popular, a que aludi.
A «cultura popular» que o Estado Novo quis formar e enformar foi, portanto, o primeiro tema que abordei sobre o Estado de Salazar e o ponto de partida de tantos estudos que vieram a ser publicados, entre eles um livro, este não citado, pelo qual tenho uma certa predilecçáo de autor, História e Ideologia (Coimbra, Minerva, 1989), que versa também a noção de "cultura" dinamizada pelo Estado Novo, no âmbito do "Povo" ou da Escola.

\section{A vinha e o vinho, um dos temas do livro}

Pode dizer-se que o estudo de João Lopes versa duas subtemáticas fundamentais: por um lado, a vinha e o vinho, na sua conjugação com os projectos do Estado Novo de Salazar; por outro, a questão da "cultura tradicional" ou da que foi também chamada "cultura popular", organizada no contexto do processo de propaganda e de afirmação ideológica do regime.

Comecemos pela vinha e pelo vinho ou da vitivinicultura (vitis+vinum +cultura). De resto, é à volta dessa temática nuclear que o livro gira, ou seja, o $\mathrm{V}$ Congresso Internacional da Vinha e do Vinho, tendo como iniciativa paralela o II Congresso Internacional Médico para o Estudo Científico da Vinha e do Vinho, e como complementos as III Festas Vindimiárias, ocorridas em Lisboa, e as II Festas das Colheitas, realizadas no Porto. Tudo se realizou a partir de 15 de Outubro de 1938.

O tema da vinha e do vinho na sua relação com os Estados autoritários, e não só, tem interessado historiadores e jornalistas. Como mero exemplo de circunstância, ainda há anos (2002) foi publicado em língua portuguesa, no Brasil, a obra (de 2001) do jornalista 
americano Don Kladstrup (vencedor de vários prémios, entre eles de três Emmys) e de sua mulher Petie, Wine and War. The Frenchs, the Nazis and the battle for France's greatest treasure (Os franceses, os nazistas e a batalha pelo maior tesouro da França, Rio de Janeiro, Jorge Zahar Editor, 2002). O vinho vende livros, não só de e para especialistas e apreciadores de vinho, mas para interessados na sua história e nas suas histórias. Em Portugal Dulce Freire, doutorada em História Económica e Social Contemporânea pela Universidade Nova de Lisboa, tem sido a melhor estudiosa do tema, tendo publicado, já depois da obra de João Lopes, a sua dissertação de mestrado, apresentada em 1997, Produzir e beber. A questão do vinho no Estado Novo (Lisboa, Âncora, 2010). E não se deve esquecer ainda, num plano mais geral, em termos de faixa cronológica, e mais específico, em termos de temática, a obra de Vital Moreira, que foi a sua tese de doutoramento, O governo de Baco. A organizaçâo institucional do Vinho do Porto (Porto, Afrontamento, 1998).

A importância fundamental da vinha e do vinho, que foi um dos produtos mais significativos da economia portuguesa, assim como o foi (e é) de países como a França ou a Itália - na visita que fiz a Dovia di Predappio (Forlì), na Emília Romagna, pude ver uma interessante exposição sobre cartazes relativos ao vinho na época do fascismo, que estava precisamente exposta na casa reconstruída onde nasceu Mussolini - , está, para o caso do Estado Novo, sintetizada no simbolicamente importante cartaz, onde se vê um copo rodeado de espigas de trigo e o texto tão conhecido: "Beber vinho é dar o pão a 1 milhão de portugueses”.

Mas, se quisermos uma afirmação porventura mais elucidativa sobre as pretensas virtudes médicas do vinho (recordemos que o livro de João Lopes abordou também a realização do II Congresso Internacional Médico para o Estudo Científico da Vinha e do Vinho), respiguemos, do texto que serviu de base a uma palestra proferida na Emissora Nacional no dia 30 de Julho de 1936 pelo médico e publicista algarvio Augusto d'Esaguy, justamente intitulada "O vinho refaz o homem", uma parte elucidativa. Ouçamos, pois, algumas das suas propagandeadas características milagrosas (quando digerido - salientava-se — em pequena quantidade e se não houvesse contra-indicaçôes):

Tem curado milhares de doentes, amparado o homem nas suas grandes crises; é o inimigo declarado da tuberculose, aumenta a longevidade.

Tem sido empregado para combater a gripe, a prisáo de ventre, as diarreias, as colites muco-membranosas, as dispépsias, os estados nauseosos e os vómitos, a tuberculose, o abcesso do pulmão, a gangrena pulmonar, a pneumonia e a bronco-pneumonia.

Os vinhos de média graduação têm sido empregados com êxito no tratamento das avitaminoses, o escorbuto, a pelagra e o beriberi; nas doenças de origem hídrica, as febres tifóides, a disenteria, a cólera e na convalescença de quase todas as doenças. É um alimento precioso, favorece o processo digestivo, aumenta a força do indivíduo. Trata-se de um reconstituinte energético, aumenta a hemoglobina e os glóbulos do sangue. É, conjuntamente, um alimento e um medicamento: um complexo de substâncias individualizadas, úteis na vida normal e nos estados patológicos.

É, a um passo, um alcalinizante, um tónico, um mineralizante e um reconstituinte.

(Boletim da Emissora Nacional. N. ${ }^{\circ} 12$, Julho de 1936, p. 17-18) 
Porém, nos inícios da EN outras palestras foram proferidas sobre o tema vitivinícola, como, por exemplo, "A campanha do vinho", proferida por Albano Homem de Melo, em 9 de Setembro de 1935 (Boletim, n.o 2, p. 50), ou "A organização dos vinicultores", proferida por António Batalha Reis, em 8 de Outubro desse mesmo ano (Boletim, n. ${ }^{o} 3$, p. 35).

Desta forma, era lógico que congressos sobre a vinha e o vinho e sobre o estudo das suas propriedades médicas interessassem muito ao Estado português, "República corporativa" (de acordo como artigo $5 .^{\circ} \mathrm{da}$ Constituiçáo de 1933), mas que era sobretudo um Estado autoritário, de grande reprodução ideológica, que organizou a sua própria propaganda (é de 1933 o Secretariado de Propaganda Nacional), bem como o seu aparelho repressivo (a PVDE, Polícia de Vigilância e Defesa do Estado, criada também nesse ano de 1933) e se quis apresentar como alternativa de "sistema" - Estado Novo. João Lopes percebeu a importância disso e, assim, integrando Portugal no que Duby chamou a "Europa das Ditaduras", mas também na Europa de alguns estados liberais e democráticos que tentavam pacificamente equilibrar a vida do continente, nesses anos trinta que antecederam a Guerra (recorde-se que no próprio ano dos congressos do vinho, 1938, realizou-se o tratado de Munique, que supôs já a anexação dos Sudetas pela Alemanha nazi), analisou a organização dos congressos por Portugal.

Indigitado para organizar o referido Congresso Internacional da Vinha e do Vinho, no anterior congresso realizado na Suíça, em Lausanne, em 1935, o Estado de Salazar, que tinha então como ministro da Agricultura Rafael da Silva Neves Duque (foi ministro já no primeiro governo de Salazar, a partir 23 de Novembro de 1934 e, depois, no renovado governo de um momento de afirmação do Estado Novo, de 18 de Janeiro de 1936 a 28 de Agosto de 1940), formado em Direito e grande proprietário agrícola no concelho da Chamusca, sobretudo na área vitivinícola, integrando, antes de ser ministro, a direcção da Federação dos Vinicultores do Centro e Sul de Portugal (1933-1934), fez um esforço notório para que esses eventos fossem um sucesso, náo deixando nada ao acaso. A delegação portuguesa ao V Congresso foi chefiada pelo engenheiro agrónomo, professor do Instituto Superior de Agronomia, Joaquim Vieira Botelho da Costa, personalidade de renome internacional. No caso dos presidentes dos congressos, enquanto Edouard Barthe, socialista que veio episodicamente a aderir ao governo de Pétain, mas que se tornou depois um antifascista, era o presidente do V Congresso Internacional da Vinha e do Vinho, era presidente do congresso médico Georges Portmann, professor de Medicina, que veio a ser Secretário Nacional de Informação do governo de Vichy e, apesar da sua acção secreta de protecção a judeus e de ter pertencido à Resistência, veio a ser suspenso após a Libertação, embora em breve tivesse sido reintegrado por decisão do Supremo Tribunal de Justiça. Pode, pois, dizer-se que desde o ministro, pela sua representatividade política, há simultaneamente uma intenção tecnológica e ao mesmo tempo ideológica, como, de resto, se pode ver através dos vários passos da organização detalhados por João Lopes.

Uma das acçôes significativas foi o esforço no sentido de que os congressistas pudessem passar por Espanha, ainda em guerra civil, havendo, por isso e por motivos de fundo ideológico, a ideia, sempre presente, de que náo poderiam participar países comunistas. Assim estiveram presentes no congresso delegaçóes de estados e de regióes francófonas dependentes, 
todos vinhateiros, cuja grande parte se integrava no bloco dos Estados autoritários/totalitários. Para além de Portugal, a Alemanha nazi, a Espanha nacionalista e a Itália fascista, estados de governo autoritário como a Bulgária, a Grécia de Metaxas, a Hungria de Horthy, a Roménia de Carol II e, depois, de Antonescu, ou a Jugoslávia, de Alexandre I, nações dependentes da França como Argélia, Marrocos e Tunísia, estados sul-americanos como Argentina, Chile e Uruguai e, finalmente, estados democráticos, como a França, o Luxemburgo e a Suíça.

Portanto, Joáo Lopes carrila elementos fundamentais para conhecer as relações da vinha e do vinho com os regimes políticos. Neste caso toda a programação dos Congressos - como veremos - tinha como objectivo relevar o papel de Portugal no contexto de uma Europa à beira do conflito. Daí a importância que teve, a ponto de o $\mathrm{V}$ Congresso ter merecido uma série filatélica específica lançada nesse ano de 1938 e um documentário cinematográfico, de José Adolfo Coelho, também desse mesmo ano. Deve recordar-se, mais uma vez, que não só o vinho correspondia a um dos segmentos mais importantes da produção nacional e da exportação, mas também que Salazar pertencia a uma das zonas mais afamadas de vinho - a região demarcada do Dão, que o foi em 1907-1908, altura em que foram demarcadas também outras regiōes (Vinhos Verdes, Colares e Bucelas, para além das regiôes demarcadas dos vinhos generosos, Porto, Carcavelos, Setúbal e Madeira, que foram sendo consagradas em épocas diferentes, no caso do Porto desde o Marquês de Pombal). Curiosamente a região célebre dos vinhos da Bairrada só foi demarcada em 1979, o que não obstou que não se lhe desse grande importância. Assim, no V Congresso, uma das visitas que se realizou teve como destino a regiâo do Buçaco, ex-libris do turismo português, e, particularmente, a Estação Vitivinícola de Anadia. Voltando ao Dáo, recorde-se que Salazar engarrafava os seus vinhos em garrafas próprias, onde se vê em relevo a sua proveniência, "Quinta das Ladeiras Santa Comba Dáo", vasilhame preparado para ele provavelmente pela Fábrica da Fontela (Figueira da Foz) e encomendado por Bissaya Barreto.

Portanto, o trabalho de João Lopes Filho é do maior interesse neste tema. Apenas poderei formular duas questóes críticas: Porque não analisou as comunicaçóes apresentadas nesse congresso — ou nesses congressos —, que foram publicadas (pelo menos algumas) e que se encontram na Biblioteca Nacional, que seriam, com certeza, da maior importância para um conhecimento mais aprofundado do tema ou dos temas em apreço? Porque não se referiu com algum significado aos anteriores congressos e aos posteriores, até porque o VI Congresso da Vinha e do Vinho se realizou na Alemanha, em 1939, na estância de Bad Kreuznach, quando a guerra se estava a iniciar?

\section{A “cultura tradicional" e a "cultura popular” no Estado Novo}

Esta é, pois, a segunda subtemática do livro de João Lopes Filho, talvez mesmo a mais importante ou aquela a que deu maior relevo, como até se vê pelo título do livro. Na verdade, toda a programaçáo dos citados congressos e das festas que lhe foram agregadas tem que ver com concepçóes e problemas referentes a estes assuntos.

João Lopes procurou integrar e explicar os conceitos, que, de resto, eu tinha tentado definir, com Carvalho Homem, desde 1982, no citado artigo sobre as 
bibliotecas das Casas do Povo, ainda que outros autores tivessem depois vindo a abordar de forma mais alargada os temas em trabalhos de fundo, nomeadamente em teses de mestrado. Recorde-se os casos de Daniel Melo (Salazarismo e cultura popular. 1933-1958, Lisboa, Imprensa de Ciências Sociais, 2001, publicação da tese de mestrado datada de 1997) e de Jorge Ramos do Ó (Os anos de Ferro. $O$ dispositivo cultural durante a "Politica do Espírito”. 1933-1949, Lisboa, Estampa, 1999).

$\mathrm{Na}$ verdade, tudo se conjugava numa concepção de "cultura tradicional": desde a música, de compositores ligeiros ou clássicos, como Frederico Valério, Belo Marques, Pedro de Freitas Branco ou Ruy Coelho - por vezes apresentados neste teatro, ligado à FNAT (ver Nuno Domingos, A Ópera do Trindade. O papel da Companhia Portuguesa de Ópera na "política social" do Estado Novo, Lisboa, Lua de Papel, 2007) — ao cliché do Folclore e dos ranchos ditos "populares"; desde o ensino virado para os "grandes heróis" ao "teatro do povo" e ao "cinema ambulante"; desde a referência turística aos "lugares sagrados" da portugalidade aos cortejos históricos e às marchas populares; desde os concursos como o simbólico "A aldeia mais portuguesa de Portugal" (que atribuiu o "galo de prata" a Monsanto) e à emblemática "casa portuguesa", representada por Raul Lino, que mergulha as suas raízes no nacionalismo dos finais do século XIX, à ideia de uma "arte popular" que atribuiu esse nome a um museu (estudado por Joana Damasceno no livro agora publicado, Museus para o Povo Português, Coimbra, Imprensa da Universidade, 2010) e que inspirou o "Portugal dos Pequenitos", da Fundação Bissaya Barreto, de Coimbra; desde o etnografismo nacionalista de Luís Chaves ao monumental livro Portugal.
Breviário da pátria para os portugueses ausentes, colectânea de textos coordenada por António Ferro (Lisboa, Ediçôes SNI, 1946) para os emigrantes portugueses (tema estudado por Heloísa Paulo em "Aqui também é Portugal”. A colónia portuguesa do Brasile o Salazarismo, Coimbra, Quarteto, 2000) e às bibliotecas das Casas do Povo, de Centros de Recreio Popular ou de colónias de férias da FNAT, devidamente escolhidas e com colecçóes dirigidas ao Povo e às Escolas.

João Lopes vai, pois, enquadrando o "programa das festas" do V Congresso com reflexóes deste tipo, que o levam, inclusivamente, ao problema complexo que foi analisado especificamente por Maria Filomena Mónica: a questão do analfabetismo no Estado Novo (" "Deve-se ensinar o povo a ler?»: a questão do analfabetismo. 1926-1939", in Análise Social, vol. XIII, 50, 1977, pp. 321-353). A nosso ver, apesar de algumas afirmações ou dúvidas de políticos e intelectuais mais conservadoras (é famosa a declaração da escritora Virgínia de Castro e Almeida, a qual, todavia, colaborou activamente nos programas de "cultura popular" do SPN) que punham sobretudo em causa a importância da alfabetização urgente e total num país marcado pelo analfabetismo - de resto herdado da Primeira República, apesar da sua profissão de fé na importância das letras (apenas se passou de $75,1 \%$ de analfabetos, em 1910, para 67,8\%, em 1930) —, o que o Estado Novo defendia não era o analfabetismo em si mesmo (como certos críticos chegaram a afirmar, visando a ideia de que se tratava de um "Estado obscurantista"). Era sim uma alfabetização gradual e estratificada, em função dos valores de uma sociedade hierarquizada. O que estaria, sobretudo, em causa seria, pois, a formação de uma "cultura popular", que teria como fundo 
uma "cultura tradicional" (transmitida de geração em geração - tradere, que significa exactamente "transmitir"), a qual poderia ser aperfeiçoada e adaptada aos valores políticos do Estado Novo, mas não poderia atraiçoá-los. Por isso no Portugal salazarista, tal como na Alemanha nazi, se separava uma "arte" ou uma "cultura boa" de uma "arte" ou uma "cultura degenerada". António Ferro, tentando definir o famoso conceito de "cultura do Espírito", inspirado em Paul Valery, dizia:

Política do Espírito não é apenas [...] fomentar o desenvolvimento da literatura, da arte e da ciência, acarinhar os artistas e os pensadores, fazendo-os viver uma atmosfera em que lhes seja fácil criar. Política do Espírito é aquela que se opóe, fundamental e estruturalmente, à política da matéria. Política do Espírito, por exemplo, neste momento que atravessamos, não só em Portugal como no Mundo, é estabelecer e organizar o combate contra tudo o que suja o espírito, fazendo o necessário para evitar certas pinturas viciosas do vício que prejudicam a beleza, como certos crimes e taras ofendem a humanidade, a felicidade do homem. Defender a Política do Espírito é combater sistematicamente, obra da vida ou obra da arte, tudo o que é feio, grosseiro, bestial, tudo o que é maléfico, doentio, por simples volúpia ou satanismo!

("Política do Espírito e sua definiçãa”. Discurso pronunciado na sede do Secretariado da Propaganda Nacional, na primeira festa dos Prémios Literários, em 21 de Fevereiro de 1934, in Prémios Literários (1934-1947). Lisboa: Ediçôes SNI, 1950. p. 18-19).
Mas, não se pense - e João Lopes entendeu muito bem essa realidade - que o Estado Novo apenas se manteve ligado a um conceito cristalizado de "Tradição". Pelo contrário, enquanto pôde e enquanto Salazar conseguiu acompanhar o conceito de Modernidade ligado ao conceito de Tradição, tentou conjugar as duas ideias. Não esqueçamos que António Ferro foi editor do Orpheu e esteve ligado ao primeiro grupo modernista (o mesmo se passou no fascismo italiano, onde o modernismo de Gabriele D'Annunzio e de Marinetti dinamizaram os conceitos de arte). Assim, o bailado "Verde Gaio" (1940), criado por António Ferro no âmbito do SPN, conjugava as danças tradicionais portuguesas com o então chamado "ballet russo". Mas, é no domínio das artes plásticas (que mereceram estudos de Artur Portela Filho, José-Augusto França, Margarida Acciaiuolli e, mais recentemente, Nuno Rosmaninho e Luís Miguel Correia) que o Estado Novo quis afirmar a sua modernidade, numa propaganda das "obras públicas". Isto no domínio da construção de escolas, e de muitas outras instituiçôes públicas, de igrejas, de arte efémera (a Exposição do Mundo Português, 1940), por vezes transformada em arte consolidada, dos restauros, etc.

O programa dos congressos, nomeadamente do $\mathrm{V}$ Congresso Internacional da Vinha e do Vinho, é comprovativo da tentativa de mostrar a Tradição e o Progresso, o simbólico oficial e o "popular", a cultura erudita (mesmo que de fundo etnográfico) e a "cultura popular"... Não é por acaso que o congresso começou no palácio da Assembleia Nacional, que houve uma gala no Teatro ainda entáo chamado Almeida Garrett (futuro D. Maria II), que teve cobertura da Emissora Nacional, que nas festas vindimiárias se juntou um espectáculo de folclore na Estufa Fria 
com desfile de ranchos na avenida da Liberdade, onde se distribuiu vinho ao povo, que se tenham visitado os "lugares sagrados" da Tradição e da Modernidade, como os Jerónimos e a Torre de Belém, assim como o Instituto Superior Técnico e o Instituto Nacional de Estatística, de Porfírio Pardal Monteiro (ex-libris por onde passa a Maria Papoila, no filme popular de Leitão de Barros, de 1937, ou cuja obra é admirada, conjuntamente com o Bairro Social do Arco do Cego ou com as próprias estatísticas colhidas no INE, pelo comunista que se converte ao Estado Novo, na Revoluçáo de Maio, de António Lopes Ribeiro, de 1937) ou, no caso do II Congresso Internacional Médico para o Estudo Científico do Vinho e da Uva, os lugares de saúde pública, como a Maternidade Alfredo da Costa (já anterior ao Estado Novo, da autoria de Ventura Terra, mas que surge como um lugar de referência na Revolução de Maio) ou o moderno Instituto Português de Oncologia, do arquitecto Carlos Ramos.

A intenção de propagandear a "cultura popular" das regióes vinhateiras ficou clara na apresentação dos ranchos folclóricos que acompanharam as festas e as visitas a quintas e às caves das regióes demarcadas e das áreas vinícolas de eleição. Assim, apresentaram-se — segundo a descrição e o estudos dos casos feito por João Lopes - o Rancho Regional da Palhavã de Setúbal, da região do Moscatel, o Rancho Folclórico de Vil de Moinhos, da região do Dão, o Rancho Folclórico da Casa do Povo de Barqueiros, da região do vinho do Douro (ou do vinho do Porto), o Rancho "As Lavradeiras" de Carreço, da regiáo dos Vinhos Verdes, o Rancho "Os Campinos" de Vila Chã de Ourique, representativo dos vinhos do Cartaxo, o Rancho Regional de Alenquer, da Estremadura, e o Rancho Regional de Colares, da Adega Regional de Colares. Ainda actuaram na região da Bairrada "Os Esticadinhos" de Cantanhede e, no Porto e no Douro, outros ranchos do Norte, entre eles os famosos Pauliteiros de Miranda.

Os ranchos folclóricos representavam, portanto, a "cultura popular autêntica”, que atraiu as massas e os intelectuais. Recordemos que António Ferro sempre desejou fazer um filme baseado nas danças e cantares de Portugal. Pouco tempo depois da sua morte, em 1956, a sua viúva, Fernanda de Castro, escrevia o argumento para o filme de João Mendes, Rapsódia Portuguesa. Era necessário atrair o olhar dos estrangeiros que nos visitavam integrados nas várias delegações, como havia sucedido com sociólogos e antropólogos da escola da sociologia ética e terapêutica de Le Play, desde os primeiros anos do século (para não falar de políticos de direita ou até de historiadores e outros intelectuais, como Henri Massis ou Jacques Ploncard d'Assac, Gonzague de Reynold, Jesus Pabón ou John Gibbons, alguns que se puseram ao serviço do SPN/SNI ou ganharam os prémios "Camóes" concedidos à obras sobre Portugal pelo SPN). Referimo-nos a Léon Poinsard, autor de Le Portugal inconnu (1910), que teve a colaboração de João Serras e Silva, professor da Faculdade de Medicina e amigo pessoal do jovem Salazar, e a Paul Descamps, autor da obra Portugal: la vie sociale actuelle (1935).

Em conclusão: Procurava-se apresentar Portugal como um país de Tradição e de Progresso, onde havia uma forte "cultura tradicional" e, ainda, ao mesmo tempo que na Europa havia já conflitos surdos ou declarados anunciadores da guerra, tentava vender-se a ideia de que Portugal era um oásis de paz que sabia bem receber. É esse o sentido das palavras de Rafael Duque na abertura do V Congresso. Estávamos em 1938. Dificilmente já a arte de bem 
receber seria conseguida com eficácia em 1940, aquando da Exposição do Mundo Português, apogeu do Duplo Centenário da Fundação e da Restauração, tempo em que os exércitos se batiam ferozmente. Mas, mesmo assim, era essa a imagem que se queria fazer passar, como se vê no filme $O$ Pátio das Cantigas, de Francisco Ribeiro (Ribeirinho), numa produção de António Lopes Ribeiro, seu irmão. Recorde-se que Ribeirinho foi o director do "Teatro do Povo".

\section{Breve ponderação sobre o livro}

A obra de João Lopes Filho é uma obra aparentemente simples e de leitura fácil, sobre um tema específico, que esconde, todavia, a complexidade dos bons estudos, de uma obra que, no seu enquadramento, nos leva a interrogar-nos constantemente, propondo questóes que merecem outras pesquisas. Daí o facto de eu ter acabado por escrever um longo texto para apresentá-la. Bom sinal, pois, para mim, a história não é, sobretudo, a solução, mas o problema, e interessam-me particularmente livros e artigos que, na verdade, se questionam e questionam o leitor. E não foi fácil, devido às actuais circunstâncias de saúde, escrever, e escrever tanto. Se o fiz foi porque valia a pena.

Luís Reis Torgal Coordenador de Investigação do CEIS20 